\title{
Newborn Polymorphonuclear Leukocyte Aggregation: a Study of Physical Properties and Ultrastructure Using Chemotactic Peptides
}

\author{
THOMAS A. OLSON, FREDERICK B. RUYMANN ${ }^{(21)}$ BRUCE A. COOK, DORIS P. BURGESS, \\ SALLY A. HENSON, AND PAUL JAN THOMAS \\ Department of Pediatric Hematology/Oncology, Walter Reed Army Medical Center, Washington, D.C. [T.A.O., \\ F.B.R., B.A.C., D.P.B., P.J.T.J and Uniformed Services University of the Health Sciences, Department of \\ Pediatrics, Bethesda, Maryland [T.A.O., F.B.R., B.A.C., S.A.H., P.J.T.] USA
}

\begin{abstract}
Summary
$N$-formyl-L-methionyl-L-leucyl-L-phenylalanine (FMLP) and $N$-formyl-L-methionyl-L-phenylalanine (FMP) were used to investigate neutrophil (PMN) aggregation. Neutrophils were isolated from healthy adult volunteers and term newborn cord blood. Neutrophil aggregation was measured after the addition of FMLP and FMP. Adult PMN aggregation curves demonstrated initial aggregation with slow deaggregation. Newborn neutrophil aggregation curves showed slow aggregation with no deaggregation. These results were identical to the adult and newborn neutrophil aggregation curves produced by C5a. Newborn PMN aggregates examined by scanning electromicrography showed frequent, dense aggregates compared with fewer, less dense aggregates of adult PMNs. Adult and newborn PMN aggregates differed when compared by transmission electromicrographs (EM). Newborn PMNs were tightly bound with cell membrane projections; adult PMNs were loosely bound with no cell membrane projections. Cytochalasin-B pretreated adult and newborn PMN aggregates displayed close approximation of cell membranes with large numbers of cytoplasmic projections.

Newborn neutrophils are irreversibly aggregated by FMLP and FMP whereas adult neutrophils display an aggregationdeaggregation reaction. EM studies suggest that this irreversible aggregation of untreated newborn neutrophils may differ from the irreversible aggregation of cytochalasin-B pretreated neutrophils.
\end{abstract}

\section{Abbreviations}

$\mathrm{CB}$, cytochalasin- $\mathrm{B}$

FMLP, $N$-formyl-L-methionyl-L-leucyl-L-phenylalanine

FMP, $N$-formyl-L-methionyl-L-phenylalanine

PBS, phosphate balanced salt solution

PMN, polymorphonuclear leukocyte

ZAS, zymosan-activated serum

Previous studies have shown marked differences between adult and newborn neutrophil aggregation induced by C5a $(5,9)$. C5ainduced aggregation in adult neutrophils is a biphasic phenomenon involving aggregation followed by deaggregation. C5a-induced aggregation of newborn neutrophils shows aggregation only (8). It has been shown that CB-pretreated adult neutrophils behave more like newborn neutrophils when aggregation is induced by C5a $(6,8)$. FMLP and FMP have been shown to act similarly to $\mathrm{C} 5 \mathrm{a}$ in producing biphasic aggregation-deaggregation in adult neutrophils $(12,15,16)$.

\section{MATERIALS AND METHODS}

Preparation of neutrophils. Citrated peripheral venous blood samples from 25 healthy adult volunteers and venous cord blood from 25 full-term infants were collected simultaneously and centrifuged on Ficoll-Hypaque gradients followed by Dextran sedimentation (3). Leukocyte suspensions were obtained after erythrocyte lysis with hypotonic saline. Leukocytes were washed in Hank's balanced salt solution (Microbiological Associates, Inc., Bethesda, MD). Leukocytes thus obtained consisted of 9094\% neutrophils.

Preparation of aggregating agents. FMLP and FMP (Sigma Chemical Co., St. Louis, MO) were dissolved with $100 \lambda$ dimethylsulfoxide and further diluted with PBS. ZAS was prepared by a modified method of Vallota (17). Zymosan (Sigma Chemical Co., St. Louis, MO) was washed twice with normal saline, then centrifuged at $2000 \times g$ for $15 \mathrm{~min}$ and resuspended in $\mathrm{AB}$ human serum to a concentration of $50 \mathrm{mg} / \mathrm{ml}$. This suspension was incubated at $37^{\circ} \mathrm{C}$ for $30 \mathrm{~min}$, then centrifuged at $2000 \times g$ for $15 \mathrm{~min}$ to remove the zymosan. The supernatant was removed and stored at $-70^{\circ} \mathrm{C}$.

Neutrophil aggregation assay. Paired adult and newborn neutrophils were adjusted to an equal concentration in the range of $5 \times 10^{6}$ to $1.5 \times 10^{7}$ (mean $8.5 \times 10^{6}$, median $7.6 \times 10^{6}$ ) cell $/ \mathrm{ml}$ using Gey's balanced salt solution (Microbiological Associates, Inc., Bethesda, MD) with $2 \%$ albumin and stored on ice.

Neutrophil suspensions $(0.4 \mathrm{ml})$ were placed in cuvettes equipped with silicon stir bars and aggregation was studied using a modified method of Craddock (5). A Sienco Dual Channel Aggregation Meter (Morrison Co.) was standardized using 1:1 dilution of cells at $95 \%$ transmission and undiluted cells at $0 \%$ transmission. After temperature equilibration at $37.5^{\circ} \mathrm{C}$ with a stir rate of $900 \mathrm{rpm}$, varying concentrations and volumes of FMP and FMLP were added and aggregation curves were obtained. Dose response curves were done on adult and newborn PMNs with FMP and FMLP. Change in transmission $(\Delta \mathrm{T})$ was measured as the percentage change in light transmission from $1 \mathrm{sec}$ after dilutional effect until $1 \mathrm{~min}$. Subsequently, aggregation was studied with adult and newborn PMNs preincubated with $20 \mu \mathrm{l}$ of $\mathrm{CB}(0.1 \mathrm{mg} / \mathrm{ml})$ (Serva, Heidelberg, Germany) for 5-10 min before addition of FMP and FMLP.

Scanning electronmicroscopy preparation. A suspension of neutrophil aggregates was put into a micro well that contained a cover slip. The micro wells were incubated in a $5 \% \mathrm{CO}_{2}$ incubator at $37^{\circ} \mathrm{C}$, resulting in neutrophil adherence to the cover slip. Cover slips were then washed three times with PBS without drying.

The cover slips were fixed with $2 \%$ gluteraldehyde. They were then washed with PBS and dehydrated with increasing concen- 
trations of ethanol, dried in a critical point dryer, and molded for electromicroscope studies. Studies were done on a JEOLJSM35 scanning electromicroscope.

Transmission electronmicrograph preparation. Aggregates were fixed as pellets in gluteraldehyde, then fixed in osmium tetrachloride, embedded in EPON, sectioned with a diamond knife and stained with uranyl acetate and lead citrate. They were examined in a Zeiss EM10 transmission electronmicroscope or a Phillips 400.

\section{RESULTS}

Representative, FMLP- and FMP-induced, aggregation curves for adult and newborn neutrophils are shown in Figures 1 and 2. The addition of FMLP and FMP to adult neutrophils produced an initial rapid increase in light transmission due to dilution, followed by an increase and decrease in transmission. When FMLP and FMP were added to newborn neutrophils, a dilutional increase in light transmission was seen again, but this was followed by an increase in light transmission without any subsequent decrease as seen in the adult cells.

Minimal concentrations for aggregation as well as the concentrations required to have optimal aggregation $(>10 \% \Delta \mathrm{T})$ are shown in Table 1. Adult and newborn PMNs pre-incubated with $\mathrm{CB}$, then treated with FMP and FMLP, displayed monophasic, augmented aggregation (Fig. 1 and 2).

Scanning electromicrographs of adult PMNs aggregated by FMP and FMLP revealed small sparse aggregates (Fig. 3). In contrast, newborn PMNs appear to form large, dense aggregates with microprojections (Fig. 4). Transmission electromicrographs were obtained at the peak of aggregation by FMLP. Newborn PMNs aggregated with close approximation and small projections of their cytoplasmic membranes (Fig. 5). Adult PMNs, after similar treatment, were less tightly aggregated without cytoplasmic extensions (Fig. 6). When both adult and newborn PMNs were preincubated with $\mathrm{CB}$, very tight aggregates were formed with a multiplicity of cell membrane projections (Figs. 7 and 8). These electromicrographs are representative and similar to those obtained with FMP and ZAS.

\section{DISCUSSION}

In this report FMLP and FMP, chemotactic peptides, induced newborn neutrophil aggregation curves identical to the monophasic, irreversible aggregation curves reported with $\mathrm{C} 5 \mathrm{a}$ and ZAS (8). Craddock et al. $(4,5)$ have shown that C5a is the active agent in ZAS leading to aggregation. Normal adult neutrophil aggregation is biphasic and represents reversible aggregation as confirmed by cell channelizer techniques (11). A clear separation was made between the monophasic aggregation of newborn PMNs and the biphasic, aggregation-deaggregation of adult cells by aggregometry. The use of FMLP and FMP demonstrates that irreversible aggregation is not a unique property of C5a. FMP and FMLP are commercially available and more practical substitutes for C5a.

Dose-response curves were performed to determine the thresh-

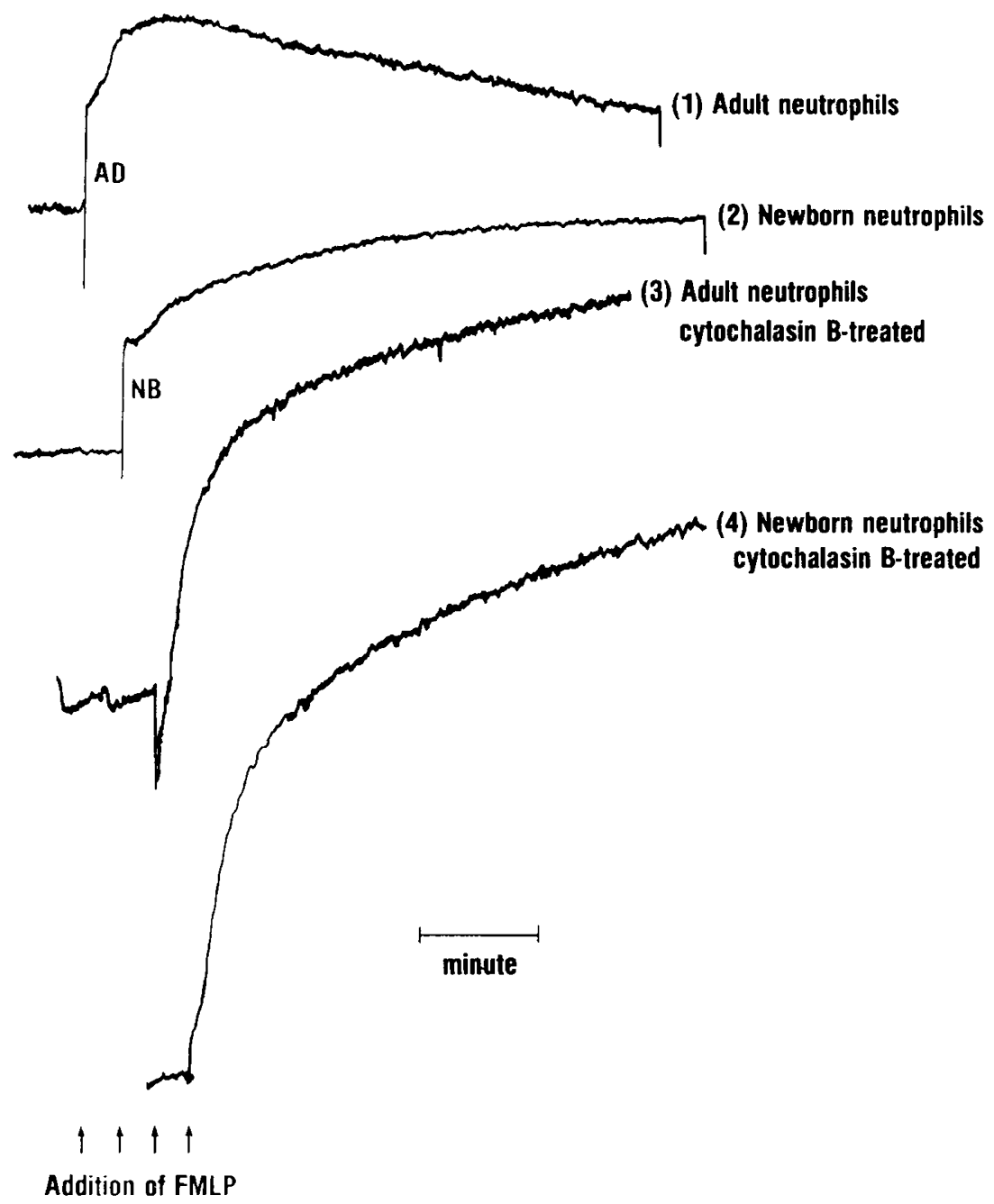

Fig. 1. Aggregation curves obtained after addition of FMLP. Vertical axis represents change in light transmission $(\Delta \mathrm{T})$. Aggregation represented as increase in light transmission. Deaggregation shown by decrease in light transmission $(\Delta T)$. 


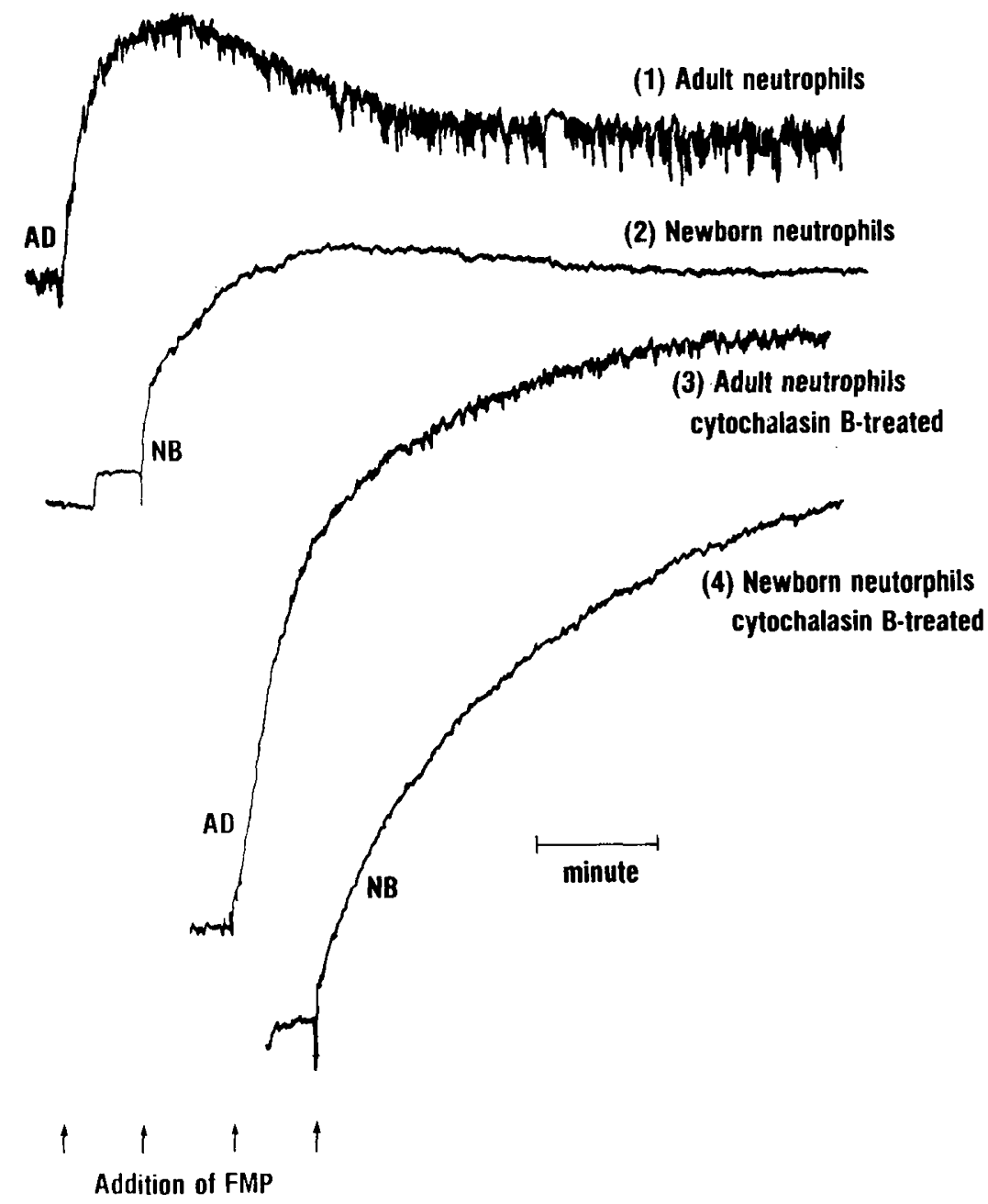

Fig. 2. Neutrophil aggregation by FMP. Vertical axis, $\Delta \mathrm{T}$.

Table 1. Molarity

\begin{tabular}{lccccc}
\hline & $\begin{array}{c}\text { Minimal molarity to } \\
\text { induce aggregation }\end{array}$ & & \multicolumn{2}{c}{$\begin{array}{c}\text { Molarity to induce } 10 \% \\
\text { or greater } \Delta \mathrm{T} \\
\text { response at } 1 \mathrm{~min}\end{array}$} \\
\cline { 2 - 3 } \cline { 5 - 6 } & Newborn & Adult & & Newborn & Adult \\
\hline FMP & $1 \times 10^{-6} \mathrm{M}$ & $2 \times 10^{-6} \mathrm{M}$ & & $8.7 \times 10^{-6} \mathrm{M}$ & $8.7 \times 10^{-6} \mathrm{M}$ \\
FMLP & $8 \times 10^{-9} \mathrm{M}$ & $2 \times 10^{-9} \mathrm{M}$ & $2.6 \times 10^{-7} \mathrm{M}$ & $1.6 \times 10^{-8} \mathrm{M}$ \\
\hline
\end{tabular}

old of newborn and adult PMNs to the chemotactic peptides. Newborn cells required higher concentrations of FMP or FMLP for aggregation than adult cells and did not display a biphasic aggregation pattern at any concentration.

Craddock et al. (6) demonstrated that the addition of $\mathrm{CB}$ resulted in a monophasic augmentation of $C 5$ a-induced aggregation of the adult PMN. When CB-pretreated adult PMNs were aggregated by FMP and FMLP, the curves obtained were similar to those using $\mathrm{C} 5 \mathrm{a}$ in earlier studies $(8,9)$. The aggregation curves, demonstrating irreversible aggregation with $\mathrm{CB}$ pretreatment, suggested that a similar mechanism might occur with the irreversible aggregation of newborn PMNs.

Craddock et al. (5) have suggested that PMN aggregation may be a manifestation of membrane interaction with complement in vitro. The precise mechanism of $\mathrm{CB}$ action is conjectural. The enhanced aggregation of adult PMNs, pretreated with $\mathrm{CB}$ has suggested that membrane ruffling may be an essential component $(14,15)$. In addition to the ultrastructure properties, $C B$ has been associated with increased free calcium in the cytoplasm (10). Increased calcium influx or concentration has been shown to augment aggregation $(5,6,13)$. The membrane changes by transmission electronmicroscopy may correlate with increased influx, but this is conjectural. Regardless of the inciting mechanism, however, increased intracellular calcium results in fusion of lysosomes with the plasma membrane and subsequent lysosomal release $(10,18)$.

Electronmicroscopy was used to explore the similarities and differences of the aggregates. Transmission electronmicrographs of neutrophil aggregates showed numerous cell membrane projections in the CB-treated adult and newborn PMN. In contrast, transmission electronmicrographs of untreated newborn PMN aggregates demonstrated fewer membrane projections than $\mathrm{CB}$ pretreated cells, but more than untreated adult PMNs. Untreated adult and newborn PMN aggregates also differed when scanning electronmicrographs were done. Scanning electronmicrographs showed that untreated newborn PMNs developed more frequent and dense aggregates than adult PMNs. The newborn PMN cell membrane projections demonstrated by electronmicroscopy may have a significant role in the prevention of deaggregation after aggregation.

The biphasic aggregation-deaggregation of adult PMNs may be an essential step in augmenting the inflammatory response (8). The formation of irreversible aggregates by CB-treated neutrophils may be responsible for inhibition of chemotaxis (1, 2, 6). Newborn PMNs aggregate irreversibly and fail to augment chemotaxis as well as adult PMNs. The deficiency may be due to differences in the cell membranes of newborn and adult PMNs.

In adults neutrophil aggregation in the microvasculature has been implicated in tissue damage (7). Granulocyte plugging of the pulmonary vasculature in response to $\mathrm{C} 5$ a has been proposed 


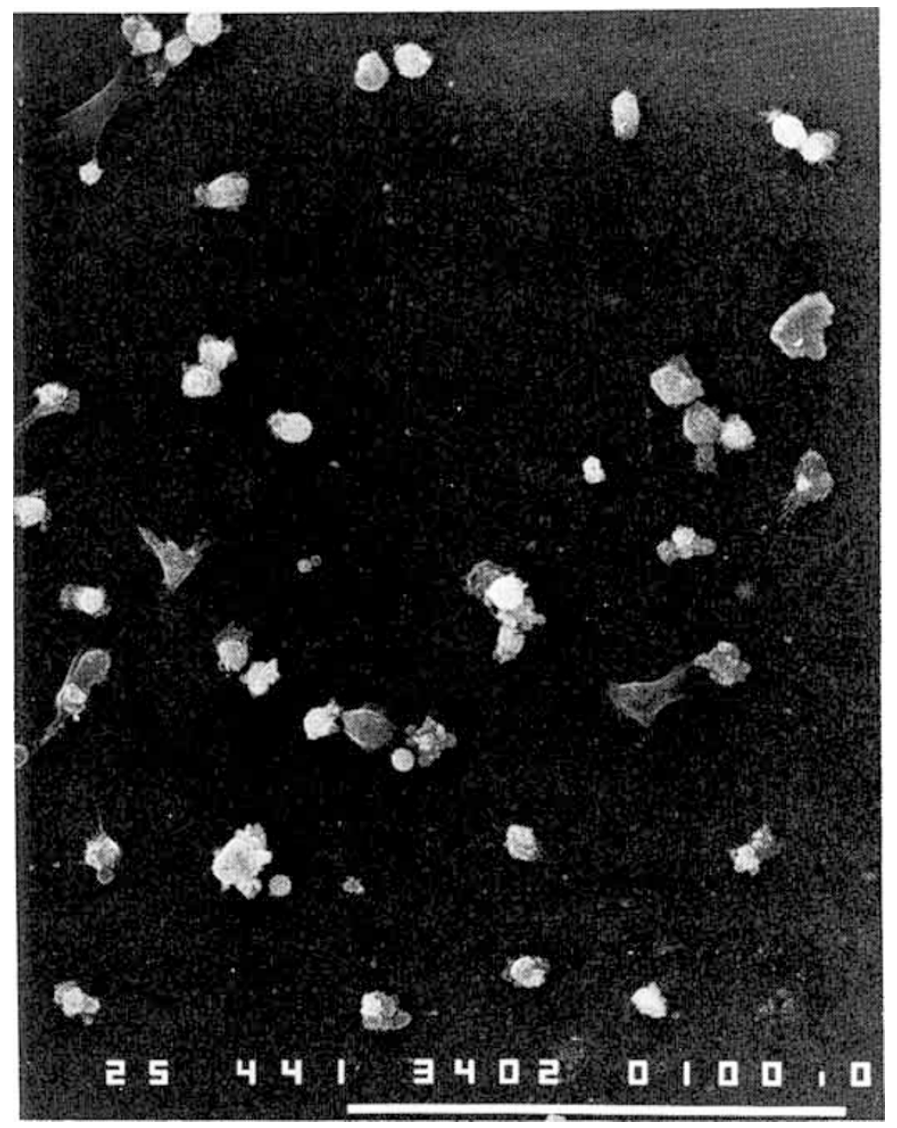

Fig. 3. Scanning electronmicrograph of adult PMN aggregated by FMLP $\left(10^{-6} \mathrm{M}\right) \times 440$. Calibration Bar $=100$ microns.

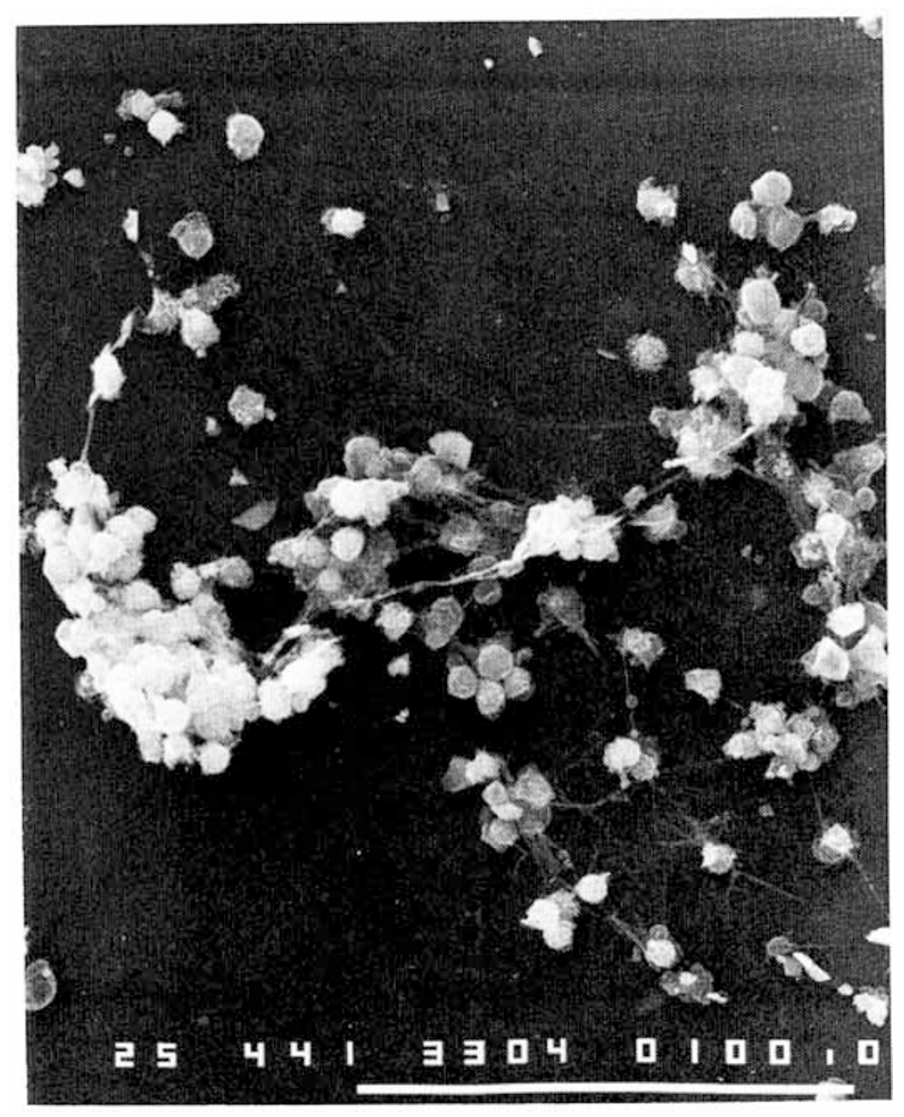

Fig. 4. Scanning electronmicrograph of newborn PMN aggregated by FMLP $\left(10^{-6} \mathrm{M}\right) \times 440$. Calibration Bar $=100$ microns.

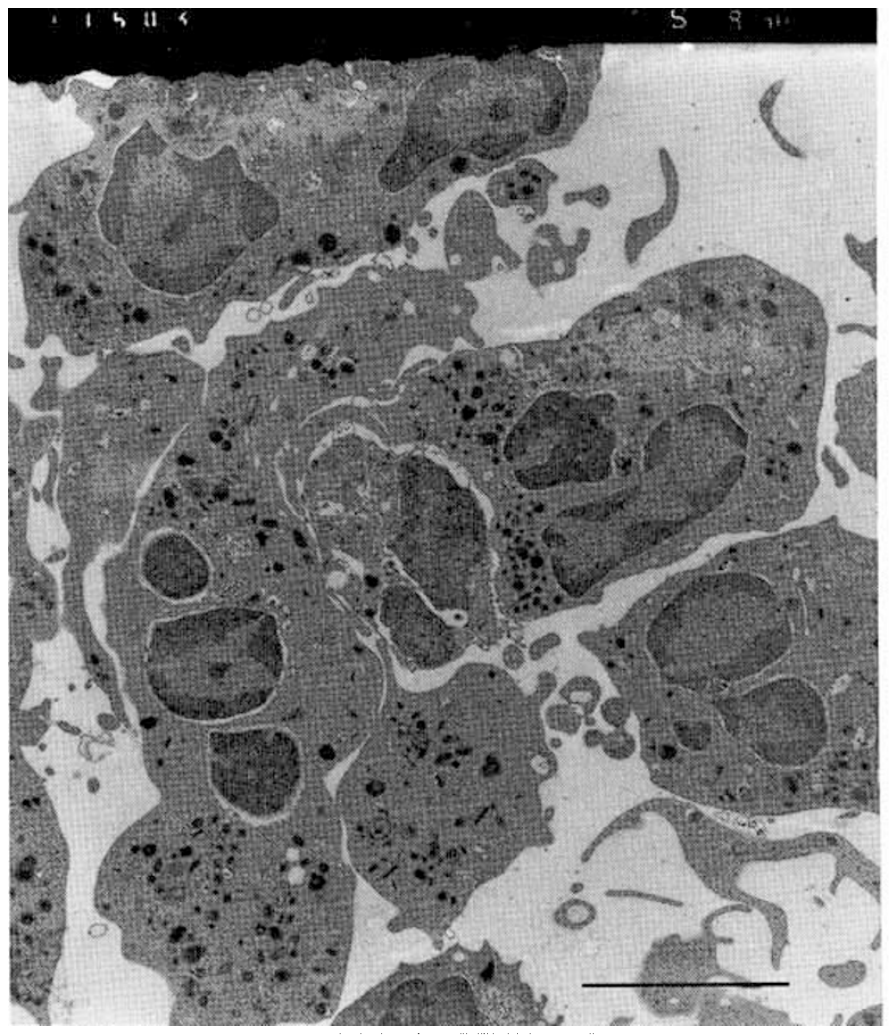

Fig. 5. Transmission electronmicrograph newborn PMNs after addition of FMLP $\left(10^{-6} \mathrm{M}\right) \times 4000$. Calibration Bar $=5$ microns.

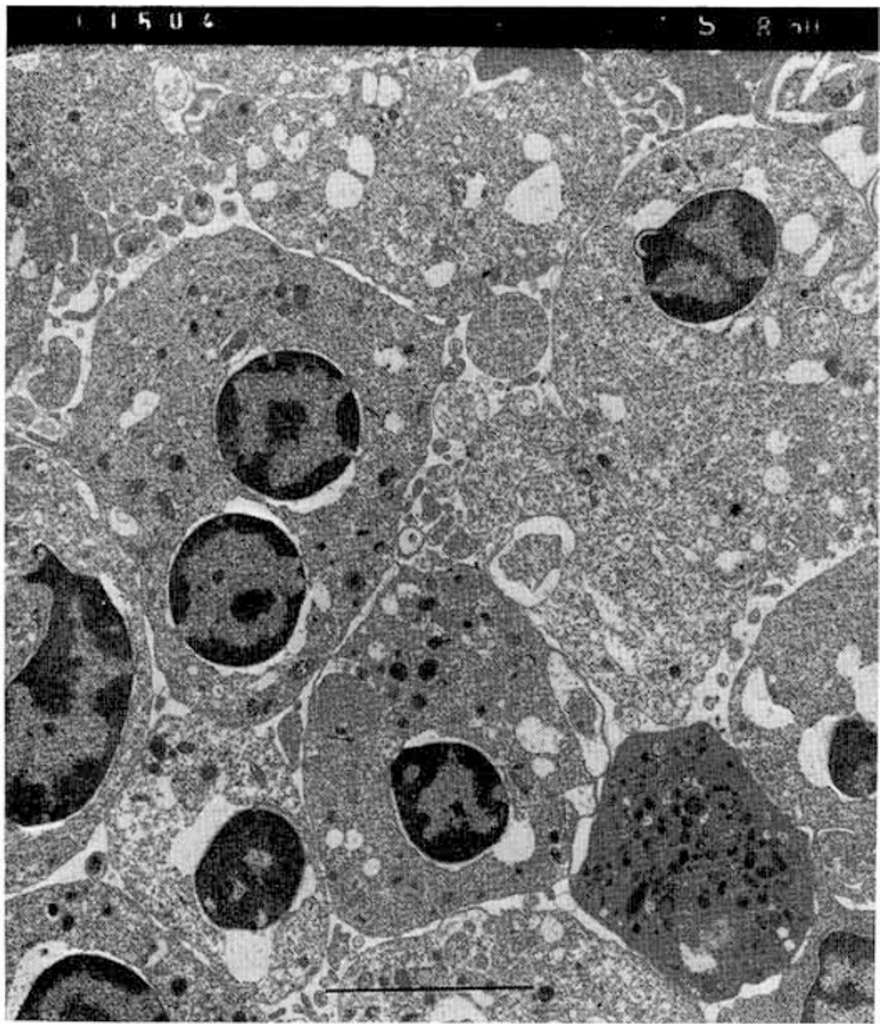

Fig. 6. Transmission electronmicrograph adult PMNs after addition of FMLP $\left(10^{-6} \mathrm{M}\right) \times 4000$. Calibration Bar $=5$ microns.

as a mechanism for the acute pulmonary dysfunction in the adult respiratory distress syndrome (7). Similarly, irreversible aggregation of newborn PMNs may result in neutrophil sequestration in the microvasculature. Several newborn disease states 


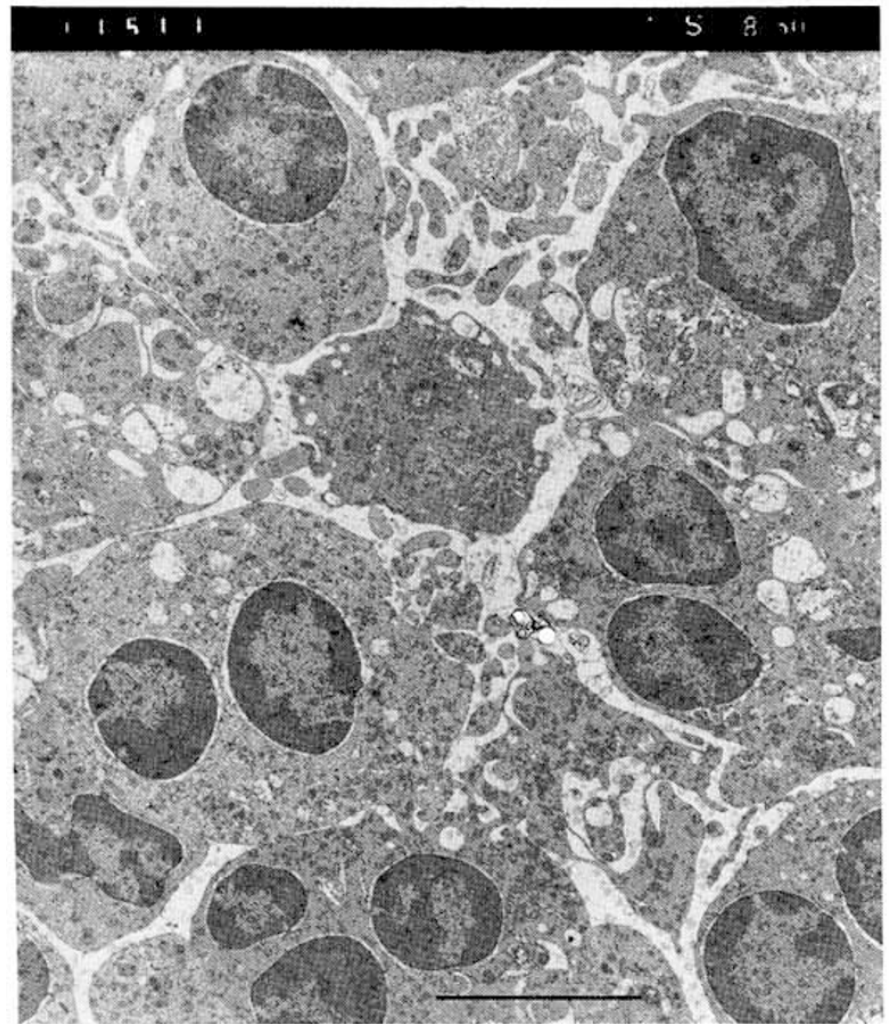

Fig. 7. Transmission electronmicrograph newborn PMNs pre-incubated with Cytochalasin B for 10 min followed by FMLP $\left(10^{-6} \mathrm{M}\right)$ $\times 4000$. Calibration Bar $=5$ microns.

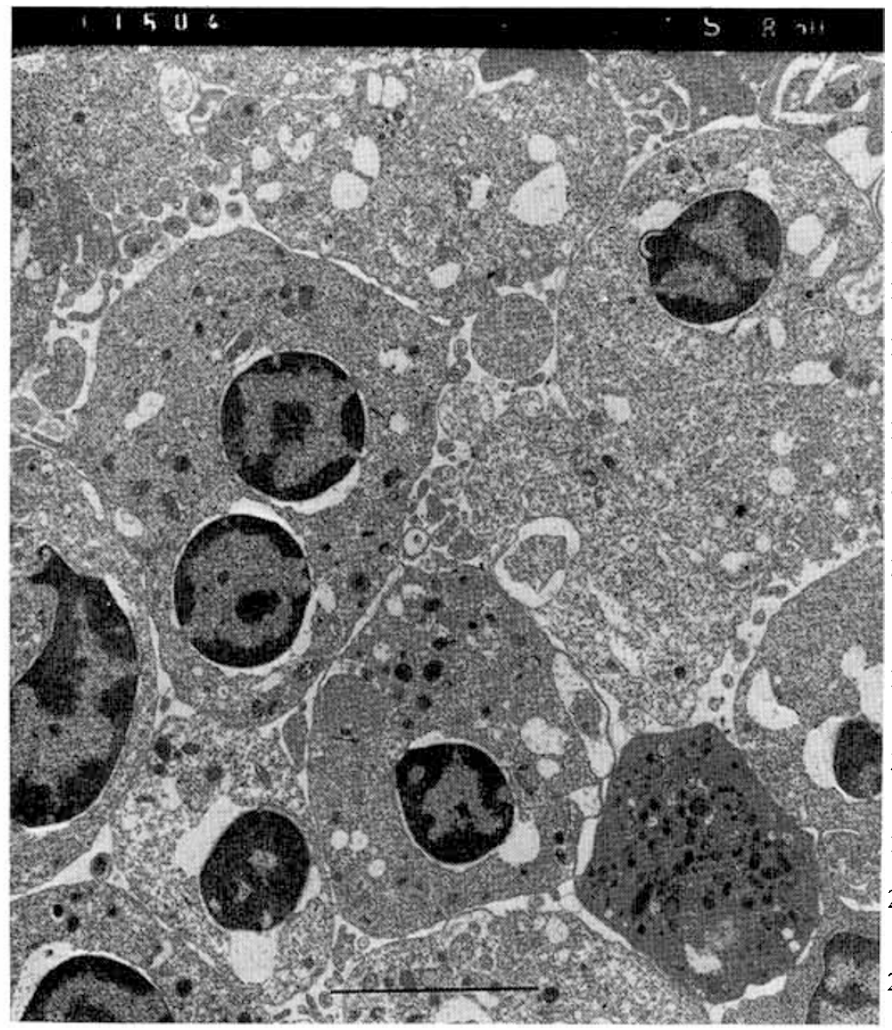

Fig. 8. Transmission electronmicrograph adult $\mathrm{PMNs}$ pre-incubated with Cytochalasin B for 10 min followed by FMLP $\left(10^{-6} \mathrm{M}\right) \times 4000$. Calibration Bar $=5$ microns. including respiratory distress syndrome in the newborn, may have a pathophysiology explained by irreversible PMN aggregation. Similarly, the vulnerability of the newborn to Group B streptococcal pneumonia may be compounded by both decreased PMN chemotaxis and PMN entrapment in the pulmonary vasculature. An improved understanding of the newborn PMNs role in this pathophysiology may lead to more descriminative treatment.

\section{REFERENCES AND NOTES}

1. Becker, E. L. and Showel, J. H.: The ability of chemotactic factors to induce lysosomal enzyme release II. The mechanism of release. J. Immunol., II2: 2047 (1975).

2. Becker, E. L. Davis, A. T., Estensen, R. D., and Quie, P. G.: Cytochalasin B IV. Inhibition and stimulation of chemotaxis of rabbit and human polymorphonuclear leukocytes. J. Immunol., I08: 396 (1972).

3. Boyum, A.: Isolation of mononuclear cells by one centrifugation and of granulocytes by combining centrifugation and sedimentation at $1 \mathrm{~g}$. Scan. J. Clin. Lab. Invest. Suppl., 97: 77 (1968).

4. Craddock, P. R., Hammerschmidt, D. E., Moldow, C. F., Yamada, O., and Jacob, H. S.: Granulocyte aggregation as a manifestation of membrane interactions with complement: Possible role in leukocyte margination, microvascular occlusion. and endothelial damage. Semin. Hematol., 16: 140 (1979).

5. Craddock, P. R. Hammerschmidt, D. E. White, J. G., Dalmasso, A. P.. and Jacob, H. S.: Complement (C5a)-induced granulocyte aggregation in vitro. J. Clin. Invest., 60: 260 (1977).

6. Craddock, P. R. White, J. G., and Jacob, H. S. Potentiation of complement (C5a)-induced granulocyte aggregation by cytochalasin B. J. Lab. Clin. Med. 91: 490 (1978).

7. Jacob. H. S., Craddock, P. R., Hammerschmidt. D. E., and Moldow. C. F Complement-induced granulocyte aggregation. An unsuspected mechanism of disease. N. Engl. J. Med., 302: 789 (1980).

8. Mease, A. D., Burgess, D. P., and Thomas, P. J.: Irreversible neutrophil aggregation. Am. J. Pathol., 104: 98 (1981).

9. Mease. A. D.. Fisher. G. W.. Hunter, K. W., and Ruymann, F. B.: Decreased phytohemagglutinin-induced aggregation and C5a-induced chemotaxis of human newborn neutrophils. Pediatr. Res., 14: 142 (1980).

10. Naccache, P. R. Showell. H. J.. Becker, E. F. and Shaafi. R. I.: Changes in ionic movements across polymorphonuclear leukocyte membranes during lysosomal enzyme release: Possible ionic bases for lysosomal enzyme release. J. Cell Biol., 75: 635 (1977).

11. O'Flaherty, J. T., Kreutzer. D. L., and Ward, P. A.: Neutrophil aggregation and swelling induced by chemotactic agents. J. Immunol.. 119: 232 (1977).

12. O'Flaherty, J. T., Showell. H. J., Becker, E. L., and Ward, P. A.: Substances which aggregate neutrophils. Am. J. Pathol., 92: 155 (1978).

13. O'Flaherty, J. T., Showell, H. J.. and Ward. P. A.: Influence of extracellula $\mathrm{Ca}^{2+}$ and $\mathrm{Mg}^{2+}$ on chemotactic factor-induced neutrophil aggregation. Inflammation, 2: 265 (1977)

14. O'Flaherty, J. T., and Ward. P. A.: Leukocyte aggregation induced by chemotactic factors. Inflammation, 3: 177 (1978).

15. Oseas, R. S., Boxer, L. A., Butterick, C., and Baehner, R. L.: Differences in polymorphonuclear leukocyte aggregating responses among several species in response to chemotactic stimulation. J. Lab. Clin. Med., 96: 213 (1980).

16. Showell, H. J., Freer, R. J., Zigmound, S. H.. Schiffmann, E., Aswanikumar S.. Corcoran. B., and Becker, E. L.: The structure-activity relations of synthetic peptides as chemotactic factors and inducers of lysosomal secretion for neutrophils. J. Exp. Med., 143: 1154 (1976).

17. Vallotta, E. H., and Muller-Eberhard. H. J.: Formation of C3a and C5a anaphylatoxins in whole human serum after inhibition of the anaphylatoxin inactivator. J. Exp. Med., 137: 1109 (1973).

18. Zurier, R. B., Hoffstein. S., and Weissmann, G.: Cytochalasin B: Effect on lysosomal enzyme release from human leukocytes. Proc. Natl. Acad. Sci. USA. 70: 844 (1973).

19. Presented in part at the Southern Society for Pediatric Research, New Orleans Louisiana, January 14-16, 1982.

20. The opinions expressed herein are those of the authors and do not necessarily represent the views of the Department of the Army or the Department of Defense.

21. Requests for reprints should be addressed to: Dr. Frederick B. Ruymann Director, Pediatric Hematology/Oncology Division, Columbus Children's Hospital. 700 Children`s Drive, Columbus, Ohio 43205 USA.

22. This research was supported by grants from the Department of Clinical Investigation. Walter Reed Army Medical Center. Washington, DC 20012

23. Received for publication May 21,1982 .

24. Accepted for publication May 11, 1983. 